\title{
O diálogo de Henriqueta Lisboa com escritoras latino americanas
}

\author{
Ana Lúcia Maria de Souza Neves*
}

\begin{abstract}
RESUMO
Neste trabalho, pretendemos analisar ensaios de Henriqueta Lisboa sobre escritoras latino-americanas com o objetivo de refletir sobre a postura da ensaísta como crítica de obras de outras poetisas. Para fundamentarmos as reflexões, buscamos embasamento teórico em Michelle Perrot, Norma Telles, Nildiceia Rocha, Del Priore, dentre outros, sobre gênero e poesia de autoria feminina. Observamos o pioneirismo de Henriqueta ao considerar em seus ensaios, sem perder de vista as condições e injunções sociais, o esforço das escritoras para fazer da sua escrita o meio para conseguir vez e voz. Destacamos também o respeito e a admiração da ensaísta pela poesia de suas contemporâneas. Em nenhum momento, a ensaísta posiciona-se de maneira a estigmatizar a produção literária das poetisas, algumas com estilo bem diferente do adotado pela poetisa mineira, pelo contrário, verificamos o destaque para aspectos expressivos que marcam a singularidade de cada poetisa. Muitos desses aspectos seriam reafirmados por outros críticos em estudos posteriores.

Palavras-chave: Henriqueta Lisboa. Ensaio. Poesia. Poetisas latinoamericanas. Gênero.
\end{abstract}

No rio a draga flutua presa à terra pelos ares

(Nosso corpo oscila a influxos de sombra e de claridade).

(LISBOA, 1985, p. 543).

\section{Introdução}

A epígrafe escolhida corresponde a uma das estrofes do poema de Henriqueta Lisboa "Notícia mineira", dedicado à amiga, também escritora, Lúcia Machado de Almeida. A leitura do poema evoca-nos uma alusão à vida das escritoras com

\footnotetext{
* Universidade Estadual da Paraíba - UEPB. Algumas das ideias aqui apresentadas foram recolhidas da tese de doutorado que se intitula Um atalho, uma clareira, coisa assim, no caminho: reflexões sobre os lugares de Henriqueta Lisboa no contexto da literatura brasileira
} 
suas dificuldades e superações: "Nosso corpo oscila a influxos/ de sombra e de claridade".

Neste artigo, pretendemos chamar a atenção para o interesse de Henriqueta Lisboa em ler e escrever sobre poetisas latino-americanas, algumas, ainda hoje, pouco conhecidas e estudadas no Brasil. É nosso objetivo destacar o pioneirismo da poetisa mineira ao assinalar o mérito da produção de autoria feminina em uma época em que a criação literária ainda era considerada por muitos como prerrogativa dos homens. (PERROT, 2010, p. 403). Pioneirismo este fruto, a nosso ver, da "mobilidade intelectual" (MARQUES, 2004) de Henriqueta e da sua postura dialógica, características que a fizeram conhecer e dialogar com poetas e poetisas independentemente das diferenças de estilo.

Para a ensaísta mineira, a crítica literária não pode perder de vista o texto, opondo-se a atitude segundo a qual a poesia modernista só poderia ser considerada com base em um único padrão. No livro de ensaios Vivência poética (1979), expressa com clareza a relação do poeta moderno com o tempo em que vive:

Nada impede que um poeta moderno se reporte a argumentos antigos, por exemplo - o anjo - símbolo estável desde que o faça em termos de atualidade, transportando-o do real para o ideal e deste para o imaginário. [...] Força é reconhecer: nenhum poeta sobrevive se se distancia do tempo que vive. O que se alienar trairá seu coração e sua consciência. Mesmo sem alusão direta a circunstâncias, o poeta se acusa como ser comunitário. Pois a crispação de uma sensibilidade ferida será mais evidente do que a denúncia ou notação de eventos. [...] A máquina, por suposto, é foco de atenção em nossos dias. Mas para que se manifeste certa atitude diante dessa cousa avassaladora, não é necessário que o vocabulário máquina figure explicitamente num texto literário. (LISBOA, 1979, p.17 - 18).

Dentre os ensaios escritos por Henriqueta, pretendemos analisar aqui um dos primeiros textos da ensaísta, "Musa hispano-americana", publicado em 1934, na Revista da Semana, periódico do Rio de Janeiro editado de 1900 a 1962. Além desse texto, discutimos sobre três ensaios presentes na coletânea Convívio poético (1955), dedicados respectivamente a Cecília Meireles (1901-1964), Alfonsina Storni (1892-1938) e Gabriela Mistral (1889-1957).

No texto publicado na Revista da Semana, Henriqueta chama a atenção para vozes femininas que, na sua opinião, são "verdadeiramente bellas e inspiradas" (LISBOA, 1934, p.32). São destacadas as poetisas Delmira Agustini (1886-1914), 
Gabriela Mistral (1888-1957), Alfonsina Storni (1892-1938), Maria Eugênia Vaz Ferreira (1875-1924) e Juana de Ibarbourou (1895-1979). Além dessas, cita as poetisas Luisa Luisi, Maria Alicia Domingues e Margarita Abella Caprille, apontadas por Henriqueta como "nomes ilustres" no "quadro de honra da poesia feminina hispano-americana". (LISBOA, 1934, p.32).

Na coletânea de ensaios Convívio poético, Henriqueta Lisboa, ao escrever, respectivamente, sobre Cecília Meireles, Alfonsina Storni e Gabriela Mistral, focaliza em singular o estilo poético de cada uma das poetisas.

\title{
2. As poetisas no ensaio "Musa hispano-americana"
}

No título do ensaio, as poetisas são designadas de "musas". O termo remetenos à figura feminina da mitologia grega que representava a fonte de inspiração nas artes e nas ciências.

A palavra "musa" foi utilizada também em referência à mulher bela que inspirava e despertava o amor. Significado recorrente no imaginário do Romantismo e que aparece em alguns poemas de Henriqueta Lisboa, escritos no mesmo período em que publica o ensaio, conforme podemos observar no poema abaixo:

\author{
Singular \\ Em vez de amar singelamente \\ uma casa pequena com jardim, \\ uma varanda com pássaros, \\ uma janela em que ao sereno há uma bilha de barro \\ um pessegueiro, uma canção e um beijo \\ - o pessegueiro de seu pomar, \\ a canção popular \\ e o beijo que poderia alcançar - \\ a minha musa ama precisamente \\ o que não existe neste lugar. \\ (LISBOA, 1985, p. 59).
}

Nos dois usos, a musa é a mulher ideal, que está em um plano superior em relação à vida material, cotidiana. Elas inspiram os artistas e aspiram a uma existência sublime. Para Henriqueta, as poetisas comentadas por ela são "representativas personalidades", que se diferenciam "das gerações em massa". Percebemos, assim, que o emprego do termo musa no título do ensaio indica uma 
construção social sobre a mulher escritora que está baseada em uma visão sobre a mulher recorrente nas primeiras décadas do século XX, ainda influenciada por uma compreensão pautada na natureza feminina como ser ideal, delicado e frágil. Apesar disso, ao contrário do pensamento da maioria dos críticos da época, que considerava as mulheres intelectualmente inferiores aos homens, e, portanto, sua forma de pensar e de escrever como menor (PERROT, 2013), Henriqueta ressalta o quanto as escritoras, cada uma a seu modo, compreendiam a sua época e com inteligência e sensibilidade escreviam sobre a realidade, na maioria das vezes adversa, que viviam:

O problema da mulher de hoje, particularmente dadas as suas características de delicadeza e fragilidade, em contraste com os horizontes subitamente abertos pelas reivindicações femininas apresenta dificuldades múltiplas, que só o tempo solucionará. Talvez para compensar o que perdeu em feminilidade, atirandose ou sendo atirada à lucta [sic], quando ainda os homens não comprehendem $[\mathrm{sic}]$ claramente seus ideaes [sic], levanta a voz em cânticos novos, poetizando a vida. (LISBOA, 1934, p. 32).

As palavras de Henriqueta revelam, embora o ensaio tenha sido publicado em 1934, a reflexão crítica sobre as condições difíceis enfrentadas pela mulher diante da postura assumida pelo masculino na sociedade. A ensaísta esboça assim seu caráter precursor no que tange à visão que colocou o feminino aquém da cultura. ${ }^{1}$

No ensaio, Henriqueta apresenta breves comentários sobre as poetisas latinoamericanas, algumas cujo lirismo mostra-se diferente do cultivado pela poetisa mineira, enveredando-se pelo cunho erótico e sensual, pelo apego à matéria, pelo desespero, decorrentes do permanente sentimento de insatisfação:

Umas, ou pela ilusão de uma força que não existe ou pela sensação da altura que gera a vertigem, criam verdadeiras tragédias íntimas, levando aos outros corações o contagioso desespero. É a paixão da matéria, o deslumbramento da liberdade, o cáos [sic] introspectivo. (LISBOA, 1934, p. 32).

1 Consideramos importante registrar que Henriqueta Lisboa foi uma das primeiras escritoras brasileira a escrever sobre as poetisas hispano-americanas. A sua contemporânea Cecília Meireles também escreveu um importante ensaio, intitulado "Expressão feminina da poesia na América", que, no entanto, foi proferido em 1956 e publicado em 1959 pelo MEC no volume Três conferências sobre cultura hispano-americana. Este fato revela o cunho precursor da ensaística henriquetiana. 
Apesar de não adotar a perspectiva lírica seguida pela maioria das poetisas estudadas, caso da uruguaia Delmira Agustini e da argentina Alfonsina Storni, Henriqueta salienta a importância da expressão lírica das poetisas: "Está neste caso Delmira Agustini, excelsa poetisa uruguaya [sic] [...]” (LISBOA, 1934, p. 32).

A primeira poetisa comentada por Henriqueta em seu ensaio é Delmira Agustini, que, na opinião da escritora mineira:

Preparou assim o próprio sofrimento [sic], imprimindo aos seus cantos nocturnos [sic] e tempestuosos um cunho de originalidade impressionante. Dir-se-ia, na apparencia [sic], que ella [sic] tinha prazer em turvar a água que lhe matava a sede. No fundo, os gestos desordenados se explicam pelo desgosto, pela amargura de saber antecipadamente que aquela água não lhe mataria a sede. $\mathrm{O}$ desejo do impossível, que resume toda a sua arte marcada de imagens febris, concretiza-se num soneto - "Lo inefable" - que se destaca no campo da poesia uruguaya [sic]. (LISBOA, 1934, p. 32).

Percebemos que a ensaísta conhece o estilo da poetisa uruguaia e, ao contrário da maioria dos críticos da época, assinala o vanguardismo da poesia de Agustini cuja expressão do sofrimento não é vista como algo superficial, mas decorre da perspicácia em perceber a condição de insatisfação que marca a existência da poetisa e de tantas mulheres da sua época, privadas de quase tudo. ${ }^{2}$

A poetisa mineira compreendeu o sentimento de insatisfação presente nos versos de Delmira Agustini. A expressão “o desejo do impossível” que ela identifica na poetisa uruguaia também é uma marca da vida e da poesia de Henriqueta Lisboa, conforme ela mesma declara em carta a Mário de Andrade em 15 de setembro de 1940:

Penso agora na minha existenciazinha... Quando eu era pequena, Mário, e alguém me dizia que não tinha qualquer cousa que eu queria, costumava bater o pé: "mas eu quero sem ter!" A frase ficou célebre na família, ainda hoje caçoam comigo. Talvez não saibam que, mesmo sem bater o pé, continuo a ser aquela teimosa

2 Segundo Galeano, "Delmira Agustini escribia em trance. Habia cantado a las filbres del amor sin pacatos disimulos, y habia sido condenada por quienes castigan em las mujeres lo que em los hombres aplauden, porque la castidade es um deber feminino y el deseo, como la razón, um privilegio masculino." (GALEANO, 1995, p. 39). 
do impossível. Não é bem do impossível, mas do ideal... (LISBOA apud SOUZA, 2010, p. 119).

A insatisfação aproxima a poesia de Henriqueta e de Delmira Agustini, no entanto, enquanto a poesia da escritora uruguaia, na visão henriquetiana, permanece presa à dor, ao sofrimento, a poetisa mineira encontrou na poesia a sublimação de sonhos irrealizáveis, transformando o amor ao impossível ou ao infinito, em poesia: "Sinto-a como aura que se irradia do ser, que preside as melhores atitudes, e que se concretiza no poema [...] considero-a desta forma, elemento fundamental e substancial da existência humana." (LISBOA, 1979, p.12).

O segundo nome apresentado no ensaio por Henriqueta é o de Gabriela Mistral. Para a ensaísta, a poesia da escritora chilena está marcada por três aspectos: harmonia, ternura humana e misticismo:

Outro aspecto, bem diverso, oferece a poesia de Gabriela Mistral, eminente professora chilena que com seu livro Desolación conquistou a admiração intellectual [sic] da América do Sul. [...] Só esta unidade interior, esta harmonia integral da inspiração e da consciência poderiam, de facto, explicar o sentido da sua obra artística, impregnada de ternura humana e iluminada de mysticismo [sic]. (LISBOA, 1934, p. 32).

Henriqueta Lisboa foi uma admiradora da poesia de Gabriela Mistral. Leu, comentou e traduziu vários poemas da escritora chilena. Em 1942, Gabriela Mistral foi a Belo Horizonte a convite de Lisboa e proferiu duas palestras, uma sobre o Chile e outra sobre o livro O menino poeta (1943), que na época se encontrava no prelo.

Há registros no Acervo dos Escritores Mineiros da UFMG de que existiu entre Henriqueta Lisboa e a escritora Gabriela Mistral um "diálogo afetuoso" por meio de cartas e de alguns encontros em colóquios e congressos de literatura.

A tradução, realizada por Henriqueta, de poemas de Gabriela Mistral para o português resultou na coletânea Poesias escolhidas, publicada em 1969. No livro encontramos um depoimento da tradutora sobre a sua admiração pela escritora chilena e sobre a amizade que existiu entre as duas: "Era o início de uma grande amizade. Nossa correspondência não foi assídua nem volumosa. Porém as vinte cartas que dela conservo são suficientes para testemunhar a ternura de seu coração". (LISBOA, 1969, p. 48). 
A admiração de Henriqueta pela poetisa chilena fará com que escreva um ensaio bastante elogioso, revelando a sua predileção pela escritora dos Andes. Retomaremos sobre este ensaio mais adiante no tópico "Gabriela Mistral: energia e ternura".

A terceira poetisa citada por Henriqueta é a argentina Alfonsina Storni. Sobre ela destaca a ensaísta:

\begin{abstract}
Alfonsina Storni, argentina, autora de vários livros de versos La inquietud del rosal, El dulce, Irremediablemente, e Languidez constitue um exemplo interessante pela impetuosidade de seu temperamento e pela variabilidade de seus motivos poéticos. Tarefa difícil seria a de classificar a quem se embriaga com uma gotta [sic] de vinho... Superficial ou profunda? Sentimental ou irônica? Lyrica [sic] ou realista? Tudo isso a um tempo. Quer dizer: humana. Mais do que isto: mulher. (LISBOA, 1934, p. 32).
\end{abstract}

Nas suas palavras, Henriqueta Lisboa aponta a dificuldade que a maioria dos críticos literários sentiu para "classificar" com base nos modelos literários preestabelecidos na época poetisas que romperam com os moldes tradicionais de criação e passaram a versar ousadamente sobre temas interditos a seu sexo, caso de Storni. Observamos, também, na leitura de Henriqueta, a ênfase na escrita da autora argentina como própria de mulher pelo seu caráter paradoxal e de difícil classificação. Posicionamento que revela a influência da visão patriarcal na crítica nas primeiras décadas do século XX em relação à produção de autoria feminina, baseada no discurso sobre "a natureza feminina":

O discurso sobre a "natureza feminina", que se formulou a partir do século XVIII e se impôs à sociedade burguesa em ascensão, definiu a mulher, quando maternal e delicada, como força do bem, mas, quando "usurpadora" de atividades que não lhe eram culturalmente atribuídas, como potência do mal. Este discurso que naturalizou o feminino, colocou além ou aquém da cultura. Por esse mesmo caminho, a criação foi definida como prerrogativa dos homens, cabendo às mulheres apenas a reprodução da espécie e sua nutrição. (TELLES, 2010, p. 403 - destaques da autora).

Alfonsina Storni, assim como Delmira Agustini, abalou a sociedade burguesa da 
sua época, fundada em binarismos "pai/mãe, homem/mulher, superior/inferior, que relacionam em última instância a mulher com o outro, a terra, a natureza, o inferior a ser dominado ou guiado pela razão superior e cultura masculina" (TELLES, 2010, p. 403).

Segundo relata seu filho Alejandro Storni (1990), para sustentar a família, a poetisa exerceu diversas atividades. Trabalhou como costureira, operária, atriz, professora e escritora. Além disso, participou da luta pelas reivindicações sociais, engajando-se ao Anarquismo.

Sua produção literária compreende diferentes gêneros: novela, conto, teatro, poesia e crítica. Mas assim como Henriqueta Lisboa, ficou conhecida pela poesia. A própria Storni fazia-se conhecer e ser reconhecida como poetisa, pois para ela, o gênero narrativo era considerado "objeto de trabalho", e os poemas, "razão de viver”. (STORNI apud ROCHA, 2013, p. 49).

Segundo Rocha, a poesia de Alfonsina Storni, "com forte tom sexual, atitudes públicas desafiadoras, irônica e imprevisível" gerou "polêmica no ambiente intelectual de sua época" (ROCHA, 2013, p. 55). Um exemplo disso foi a recepção crítica desfavorável recebida pelo primeiro livro - La inquietud del rosal (1916) "poucos exemplares são vendidos e o público a chama de escritora imoral".

Apesar das diferenças de personalidade e de estilo poético, Henriqueta demonstra admiração pela poetisa argentina, dedicando a ela, assim como fez em relação a Gabriela Mistral e Cecília Meireles, um artigo completo, que foi incluído no livro de ensaios Convívio poético (1955).

Outra poetisa citada por Henriqueta no ensaio "Musa hispano-americana" é Maria Eugenia Vaz Ferreira (1875-1924):

Uruguya, há pouco falecida, e cujas composições espalhadas em revistas foram selecionadas e publicadas em volume póstumo, com o título de 'La islã de los cânticos', alma solitária e pensativa, tinha a convicção de que nada existe na natureza ou na vida sem um motivo transcendente. Para Ella, portanto, o universo não podia ser representado senão de modo grandioso. É desta nobreza mesma que se reveste a sua arte, povoada de heróes e de estandartes. Dirigir-se à essência das cousas deve ter sido seu ideal. (LISBOA, 1934, p. 32).

Os aspectos destacados por Henriqueta na descrição apresentada sobre a vida e a obra de Maria Eugenia Vaz Ferreira com destaque para a solidão como característica que marca a vida da poetisa e o interesse pela "essência das cousas", como elemento principal da literatura realizada pela uruguaia, também serão apontados, anos depois, 
por Cecília Meireles no ensaio "Expressão feminina da poesia na América” (1959). A última poetisa comentada por Henriqueta é a também uruguaia Juana de Ibarbourou:

autora de "Las lenguas [sic] de diamante", "El cântaro fresco" e "Raiz salvaje" [sic]. Musa delicada e sensual, amorosa da terra e do amor, por instincto e adivinhação da beleza [sic] pagã canta deliciosamente pela alegria de cantar sem ansias metaphysicas [sic] nem devaneios complexos. (LISBOA, 1934, p. 32).

Outro nome de destaque na literatura hispano-americana, Juana de Ibarborou nasceu em 1895 em Cerro Largo, Uruguai, tendo, segundo Queiroz (1961), iniciado a carreira literária em 1917. Apesar de sua poesia tratar de temáticas abordadas por suas contemporâneas, Agustini e Storni, como o amor e a insatisfação, o tom dos seus poemas é bem diferente. Conforme destacam ensaístas como Queiroz, a poesia de Ibarborou "não explora como a de Agustini o caráter trágico da união, nem como a de Storni o ódio e o desprezo ao que se deseja”. (QUEIROZ, 1961, p. 18).

De modo geral, podemos sintetizar que há nas palavras de Henriqueta presentes no ensaio o reconhecimento do valor literário da expressão lírica das poetisas. A ensaísta brasileira de maneira perspicaz percebeu aspectos estéticos do estilo de cada poetisa que hoje continuam sendo assinalados e considerados merecedores de estudo, conforme podemos observar melhor nos artigos incluídos na coletânea Convívio poético (1955).

\section{As poetisas na coletânea Convívio poético (1955)}

A propósito de tratar da poesia de suas contemporâneas, Henriqueta Lisboa focaliza aspectos da trajetória de vida das escritoras latino-americanas Cecília Meireles, Alfonsina Storni e Gabriela Mistral que, assim como muitas outras na história, foram mulheres inteligentes, sensíveis e capazes, mas que, devido ao fato de estarem circunscritas dentro do universo masculino/dominante, sofreram, umas mais outras menos, a incompreensão por não se submeterem às rígidas normas impostas pela sociedade patriarcal.

É possível perceber nos ensaios de Henriqueta, ao abordar a poesia produzida por Cecília Meireles, por Alfonsina Storni e por Gabriela Mistral, a relação 
das escritoras com a vida, as angústias e frustrações, vendo a poesia que elas produziram não como confissão da vida que levavam, mas uma maneira de lidar com o sofrimento, o silêncio, a invisibilidade e a incompreensão de que eram vítimas. É assim que ela se refere, por exemplo, à poetisa Alfonsina Storni e à poesia produzida por ela: "Forte no sentido de encarar sem rebuços a realidade, transformou em motivos artísticos aquilo que a fazia sofrer [...]". (LISBOA, 1934).

Nos ensaios, Henriqueta mostra a interligação entre a poesia e a condição como cada escritora se porta na vida, sem, no entanto, cair no mero biografismo, característica dos primeiros estudos sobre as poetisas (ROCHA, 2013). Além disso, Os ensaios chamam a atenção pelo fato de dar destaque a mulheres escritoras em uma época em que elas eram "tradicionalmente vistas como expectadoras do teatro no qual se defrontavam seus mestres e senhores, os homens..." (DEL PRIORE, 2001, p. 217).

As quatro escritoras, incluindo Henriqueta Lisboa, embora oriundas de espaços geográficos diferentes, em parte tiveram uma trajetória semelhante como intelectuais das letras. Todas as quatro formaram-se como professoras, atuaram no ensino básico, escreveram poesia e dedicaram-se à crítica literária.

Esta trajetória possibilitou que cada uma, a seu modo, refletisse sobre as condições socioculturais vivenciadas e procurasse ampliar os seus espaços relativos à condição como mulher e como escritora no mundo moderno.

As palavras tecidas por Henriqueta retratam mulheres surpreendentes que, assim como a poetisa mineira, mantiveram uma atitude reflexiva e de resistência de acordo com as condições sociais em que viviam, escrevendo poesia e prosa em que ecoam as suas frustrações e os seus ideais. Para tornarem-se criadoras precisaram: "matar o anjo do lar, a doce criatura que segura o espelho de aumento, e [...] enfrentar a sombra, o outro lado do anjo, o monstro da rebeldia ou da desobediência" (TELLES, 2010, p. 408). Leitoras do mundo moderno com olhares sobre a sociedade e sobre a poesia, em alguns aspectos semelhantes, em outros diferentes.

Passemos, então, a atenção ao olhar de Henriqueta sobre a vida e a poesia de Cecília Meireles, Alfonsina Storni e Gabriela Mistral, comentando os ensaios presentes na coletânea Convívio poético (1955), dedicados a cada uma das poetisas. 


\subsection{Cecília Meireles: "do cotidiano ao indizível”}

Henriqueta Lisboa e Cecília Meireles nasceram no mesmo ano, em 1901, e estrearam no universo das letras com a publicação de obras marcadas pela influência simbolista (DUARTE, 2012). Ambas dedicaram-se à carreira docente, escreveram ensaios tematizando sobre a relação entre literatura e ensino, assim como sobre a poesia de escritoras latino-americanas e livros de poesia direcionados ao público infantil. Ao percorrer caminhos tão semelhantes, o encontro entre as poetisas era certo, o que teve início com a troca de correspondências, que se estendeu entre os anos de 1931 a 1963.

Henriqueta Lisboa inicia seu ensaio sobre Cecília Meireles destacando que, em uma "visão panorâmica", a obra da poetisa carioca apresenta "uma grande harmonia" alicerçada em três bases: 1) unida através do tempo por uma concepção de vida de sabor mais ou menos ácido; 2) sentimento místico de beleza; 3) penetrante conhecimento dos valores artísticos.

Leitora assídua da produção ceciliana, Henriqueta demonstra conhecer o estilo da poetisa carioca e mais, ao contrário de grande parte da crítica brasileira, formula claramente as semelhanças e diferenças na comparação entre o seu estilo com o de Cecília Meireles. Em entrevista concedida a Santos (1968), ao ser questionada sobre a afinidade entre a sua poesia e a de Cecília Meireles, Henriqueta destaca:

A nostalgia do espírito, a sensação do efêmero e a intuição de que a forma, reflexo do conteúdo, deve ser devidamente depurada. Por veredas diferentes, ela com sua linda voz musical, eu com timbre mais dramático, perseguimos ideais semelhantes. (LISBOA, 1968).

Em Cecília Meireles prevalece, conforme palavras da própria Henriqueta, "uma serenidade lúcida" (LISBOA, 1985, p.179). Ao contrário da poetisa mineira, em cujos versos predomina a tensão retratada na "luta da impetuosidade versus a contenção, do arrebatamento versus o controle técnico, da espontaneidade versus o artesanato, da confissão versus pudor, do desejo versus o interdito". (LUCAS, 1980, p. 8).

Além disso, diferentemente da maioria dos $\operatorname{críticos}^{3}$, que destaca o caráter

3 Bosi em História concisa da literatura brasileira, embora inclua Cecília Meireles e Henriqueta Lisboa no tópico do seu livro "Tendências contemporâneas", destaca nas poetisas "o distanciamento do real". Sobre Cecília Meireles afirma: "o poeta de Solombra parte de um certo distanciamento do real imediato e norteia os processos imagéticos para a sombra, o indefinido, quando não para o sentimento 
essencial e imanentista ao referir-se à poesia de Cecília Meireles, assim como à de Henriqueta Lisboa, a ensaísta mineira ressalta o aspecto humano da poesia ceciliana: "Longe de mostrar-se alheia à condição humana [...] Cecília costuma superar essa condição com nobreza e discrição, a que não deixam de associarse leves tons de ironia". (LISBOA, 1985, p. 180). Para a ensaísta, a lírica da poetisa carioca está voltada também para as circunstâncias sociais e históricas que envolvem a vida das pessoas na sociedade.

A linguagem ceciliana é outro aspecto que chama a atenção de Henriqueta: "sem preciosismos, valoriza as palavras quotidianas, para que elas digam o indizível. Com um número restrito de palavras realiza o milagre." (LISBOA, 1985, p. 179).

Henriqueta chama a atenção ainda, de forma pioneira, para a afinidade da poesia ceciliana com o ascetismo oriental, evidente, segundo a ensaísta, na "sobriedade de atitudes", na "dignidade dos silêncios repentinos", no "desapego à matéria". (LISBOA, 1985, p.179). Anos depois, esta afinidade será recuperada por Alfredo Bosi:

O sofrimento, que as mudanças contínuas infligem aos mortais, leva ao desejo e à intuição do nirvana, onde não há mudança. Por sua vez, a aceitação da pobreza e do absoluto despojamento é o caminho para compreender a divindade como o não-ser em face dos poderes do mundo. (BOSI, 2007, p. 25).

São destacados ainda como veio da poesia ceciliana, o inconformismo, a melancolia, a efemeridade e a poesia como ato vital: "Tudo se transforma, tudo perece, tudo é efêmero. Morre a própria beleza; mas esta, no momento em que vive, é plenitude [...].” (LISBOA, 1985, p.180).

Todos estes aspectos apontados por Henriqueta como características da expressão lírica ceciliana serão reafirmados em estudos posteriores. Dentre estes, está o texto de Darcy Damasceno, intitulado "Poesia do sensível e do imaginário", cuja primeira edição é de 1958. Segundo Damasceno:

A consciência da fugacidade do tempo - mola mestra do lirismo ceciliano - aponta pela primeira vez em algumas peças do livro;

de ausência e do nada" (BOSI, 1994, p. 461). Em relação a Henriqueta Lisboa assinala: "[...] sutil tecedoras de imagens capazes de dar uma dimensão metafísica ao seu intimismo radical [...]". (BOSI, 1994, p. 463). 
a consideração da vida como sonho, a melancolia, um toque verlainiano na pintura de ambientes completam a caracterização da temática de "Nunca mais..." [...] O conjunto de seres e coisas que latejam, crescem, brilham, gravitam, se multiplicam e morrem, num constante fluir, perecer ou renovar-se, e, impressionando-nos os sentidos, configuram a realidade física, é gozosamente apreendido por Cecília Meireles [...]. (DAMASCENO, 1993, p. 25 e 28).

Nesse sentido, é possível perceber no ensaio de Henriqueta Lisboa a sensibilidade e a perspicácia na identificação de aspectos da poesia de Cecília que posteriormente seriam estudadas como características da poetisa carioca.

\subsection{Alfonsina Storni: "um destino de lutas"}

Henriqueta Lisboa foi uma leitora assídua da poesia de língua espanhola, o que provavelmente se intensificou devido ao exercício profissional como professora de literatura hispano-americana. Além de apreciadora, dedicou-se à tradução e à crítica da poesia de vários autores, dentre estes Alfonsina Storni.

No artigo sobre a poesia de Storni, deparamo-nos com vários elogios à personalidade e à poesia da escritora argentina: "Com que talento soube conciliar essa graça com os conceitos emitidos! Emitir conceitos sem prejuízo para a poesia é privilégio raro. Alfonsina Storni o possuiu". (LISBOA, 1955, p. 184).

Segundo a ensaísta mineira, a poesia de Storni caracteriza-se por paixões, atmosfera sombria, ironia, revolta e insatisfação. Estes aspectos serão reafirmados por críticos brasileiros nas décadas seguintes como no estudo da ensaísta Maria José de Queiroz, “A poesia de Juana de Ibarborou”, no qual a estudiosa faz uma comparação entre a poesia da uruguaia com o estilo poético de Delmira Agustini, Gabriela Mistral e Alfonsina Storni. Na comparação entre Ibarborou e Storni, Queiroz ressalta sobre a poetisa argentina:

Alfonsina Storni, a insatisfeita, procura explicações e justificações para a existência. Como tôda [sic] tentativa no sentido de alcançar o amor representa nova derrota, frustrado o desejo de realização, resta lhe a amarga certeza da própria impotência e seu desprezo [sic] ao homem [...] tinge-se de ódio a concepção de amor que pretende transmitir, mas, como mulher, não pode fugir a êle [sic]. Daí, o desequilíbrio entre o desejo do amor e a repulsa à criatura amada. (QUEIROZ, 1961, p. 18). 
Em seu estudo Queiroz vê na abordagem da temática do amor o elemento que aproxima a poesia de Ibarborou, Agustini, Mistral e Storni: "O esteio de tôda [sic] a cristalização emotiva é em tôdas [sic] elas o amor. Porque no amor a mulher encontra a salvação, nêle [sic] conciliando harmoniosamente erotismo e narcisismo." (QUEIROZ, 1961, p. 16). Evidencia-se nas palavras de Queiroz a visão recorrente em estudos críticos até meados do século $\mathrm{XX}$ de que seria característico da produção feminina tematizar sobre o amor.

No que tange à poesia de Alfonsina Storni, Henriqueta menciona mudanças, na produção da escritora argentina, consideradas paradoxos decorrentes do temperamento da poetisa:

Observados em conjunto, oferecem êsses [sic] poemas um caso de desarticulação, de dissociação entre as faculdades de um mesmo ser. Paradoxo estranho é o dessa alma, cujos ideais se entrechocam e cujo êrro [sic] fundamental foi querer fazer provisão de força nas fontes da própria fraqueza. Temperamento feminino - caprichoso e irrequieto, - em contraste com uma inteligência lúcida, cuja acuidade e poder de crítica são notáveis, Alfonsina estava fadada a um destino de lutas. (LISBOA, 1955, p. 182).

Ao ler poemas produzidos em diferentes momentos da vida de Storni, Henriqueta percebe a mudança significativa entre os primeiros livros publicados entre 1916 e 1925, e os publicados depois deste período. Mas não consegue exprimir de maneira precisa as transformações, relacionadas à expressão lírica de Storni, definindo-as como paradoxos. Estas mudanças serão explicadas na contemporaneidade por estudiosos da poesia de Alfonsina Storni como fruto do amadurecimento da poetisa:

A poesia de Alfonsina Storni posterior à languidez dará voz ao sujeito feminino em seu livro de poesia intitulado Ocre [...] iniciase um período vanguardista da poeta, considerado fonte de uma nova linguagem e construção de uma outra identidade [...] sua poesia agora estará marcada pelo fluir inexorável da criatividade poética. (ROCHA, 2013, p. 90).

No estudo "A constituição da Subjetividade feminina em Alfonsina Storni: uma voz gritante na América", Nildicéia Rocha, à luz da crítica feminista e das contribuições da Análise do Discurso, afirma que os livros Poemas de amor e 
Ocre marcam o início na poesia de Storni de um pensar/ver/poetisar o mundo a partir da perspectiva de um sujeito mulher, "que se vê pensar e sentir o mundo pela consciência de si e do mundo que a cerca". Uma leitura que não podemos exigir de Henriqueta, uma vez que ela vivia em uma época em que a mulher escritora era tida como "musa ou criatura, nunca criadora". (TELLES, 2010, p. 403).

Certo é que a poesia de Alfonsina Storni desperta em Henriqueta fascínio pela força e pelas inovações apresentadas:

A técnica de que se serviu Alfonsina, sob aparência comum, é fortemente original. Estilo palpitante, nervoso, aberto em parêntesis, tecido em matizes, farto de pinceladas bruscas, acompanhando sempre as variações de sua sensibilidade. [...] Interrogações a cada momento, interjeições, apartes imprevistos marcam êsses [sic] versos de uma ardente mobilidade. (LISBOA, 1955, p. 184).

Henriqueta destaca a presença de aspectos expressivos singulares na poesia de Storni e, assim, salienta o caráter precursor da expressão lírica da poetisa. A leitura henriquetiana focaliza nos elementos linguísticos os efeitos de sentido, apresentando o modo particular da poetisa estudada se exprimir literariamente. Percebemos que a ensaísta realiza uma leitura baseada na estilística, fundamentada nos trabalhos de K. Vossler, discípulo de Benedetto Croce, Dámaso Alonso e Amado Alonso, autores citados por Henriqueta Lisboa nas referências bibliográficas do livro de ensaios Convívio poético.

\subsection{Gabriela Mistral: "energia e ternura”}

Gabriela Mistral, pseudônimo escolhido de Lucila Maria Del Perpetuo Socorro Godoy Alcayaga, nasceu em Vicunha em sete de abril de 1889 e faleceu em Nova Iorque em onze de janeiro de 1957. (EDWARDS apud LISBOA, 1969).

A vida da escritora chilena está marcada, segundo seus biógrafos, por três aspectos. $\mathrm{O}$ primeiro diz respeito às experiências dolorosas relacionadas à perda de entes queridos. Na infância é abandonada pelo pai e criada pela mãe e uma irmã mais velha; na juventude perde o namorado que comete suicídio; adulta perde o sobrinho, criado em seu lar como filho - Juan Miguel - cuja morte ficou envolta em mistério, embora os jornais tenham se referido a suicídio. 
O segundo aspecto está relacionado à sua postura como educadora, atividade que começa a exercer desde os primeiros anos da adolescência, seguindo os passos da sua irmã mais velha, e se estende por toda a vida, atuando inclusive em países como no México onde colabora na reforma educacional.

O terceiro e último aspecto diz respeito à sua "vida errante". "Esteve na Espanha, na Itália, em Portugal, Nos estados Unidos, no Brasil, no México, na América Central, nas Antilhas, em Porto Rico.” (EDWARDS apud LISBOA, 1969, p. 31).

Para os críticos, estes aspectos influenciaram a poesia de Gabriela Mistral marcada pelo sentimento de um destino trágico; procura, através do amor, dos sentimentos maternais e da natureza, de uma espécie de essência imutável; ternura pelas crianças; obsessão da morte. Além desses elementos, a poesia de Mistral, sobretudo da maturidade, destaca-se pela presença constante do folclore e das tradições religiosas dos povos indígenas americanos. (EDWARDS apud LISBOA, 1969).

Gullberg, no discurso proferido por ocasião da entrega do Prêmio Nobel de Literatura a Gabriela Mistral, assim se refere à poetisa:

Fizestes uma viagem muito longa para ser recebida por discurso tão breve. [...] Prestando homenagem à opulenta literatura iberoamericana é que nos dirigimos, hoje, à sua rainha, à poetisa de Desolacion, que se tornou a grande cantora da misericórdia e da maternidade. (GULLBERG apud LISBOA, 1969).

Percebemos no trecho citado, uma certa idealização da imagem da poetisa ("cantora da misericórdia e da maternidade"). Esta Exaltação da figura de Gabriela Mistral marca o ensaio de Henriqueta Lisboa sobre a escritora: "[...] longe estava de supor que havia de encontrá-la um dia, criatura real e humana". (LISBOA, 1969, p. 47).

A admiração de Henriqueta Lisboa pela poetisa chilena está presente nos seus depoimentos e ensaios. Na coletânea de poema de Gabriela Mistral intitulado Poesias escolhidas, traduzido para o português por Henriqueta, a escritora brasileira fala-nos da amizade que as uniu:

Admirava, desde menina, a poesia de Gabriela Mistral. Impressionavam-me, além dos belos e fortes poemas que haviam consagrado seu nome no cenário das letras hispano-americanas, as notícias em torno de sua nobre estatura moral [...]. (LISBOA, 1969, p. 47). 
Percebemos nas palavras de Henriqueta que a ensaísta coloca a poetisa chilena em um patamar elevado. No texto da ensaísta mineira evidencia-se uma linguagem simbólica, repleta de metáforas e comparações por meio da qual a figura da poetisa Gabriela Mistral é apresentada como excepcional:

Gabriela Mistral nos recorda uma figura de lenda, a figura impressionante de Hatto, o eremita de Selma Lagerloff. [...] Gabriela, que no fundo trazia uma trágica vocação, - desde que sentiu a fragilidade da criatura, principalmente da criança, escreveu cousas amantíssimas: "La oracion de la maestra", "Poemas de las madres", "canciones de cuna". A ternura revelou-lhe o sentido construtivo de sua mesma poesia, alimentada de forças [sic] adversas. (LISBOA, 1955, p. 189).

A figura da poetisa chilena chega a ser comparada, em outra passagem, à imagem de uma santa - Santa Teresa, símbolo do indefectível amor oblativo: "Encontra-se, talvez, em Santa Teresa, em amplo sentido, o seu paradigma. Para ambas a realidade é um estímulo: quanto mais rude, mais rica de consequências [sic]." (LISBOA, 1955, p. 188).

Os comentários revelam a fascinação sentida por Henriqueta frente à figura da escritora chilena. A mesma linguagem simbólica é utilizada pela ensaísta ao referirse às obras de Mistral: "Penetrado do real e sugerindo, todavia uma atmosfera de êxtase, o misticismo da autora contamina tôda [sic] obra, aquecendo-a, dramatiza-a, como fogo na selva. As árvores queimam-se e, ao mesmo tempo, iluminam." (LISBOA, 1955, p. 187-188).

O seu entusiasmo pela vida e pela obra de Mistral não impede, no entanto, Henriqueta de identificar com perspicácia traços do estilo desta poetisa, que afirmam o caráter moderno da sua poesia: "Obra de irrecusável modernidade, absolutamente nova pela substância, tem o gôsto [sic] das antigas raízes levadas pela água da chuva. Poder de síntese, firmeza de pensamento, emoção sublimada [...]”. (LISBOA, 1955, p187-188).

Para Henriqueta, a poesia de Mistral, assim como a das suas contemporâneas, é fruto da relação da poetisa com a vida, com as vivências sociais:

A artista não pede ajuda ás nuvens nem ao vento; marca a sua arte dos próprios passos, modelando-a como elemento plástico, aproximando-a da escritura e da pintura, imprime-lhe o ritmo de danças rituais religiosas e primitivas [...] Através de imagens 
concretas, por vêzes [sic] impiedosamente cruas [...] (LISBOA, 1955, p. 190).

Esta perspectiva de Henriqueta reconhece na poesia de Mistral a presença de assuntos significativos, contrária à ideia de que a poesia de autoria feminina só fala de afabilidades, fantasias, sonhos.

Henriqueta encerra o ensaio, afirmando que encontra na poesia da escritora chilena: "as qualidades exigidas por Schiller para a obra de arte: energia e ternura". (LISBOA, 1955, p. 191). Características buscadas durante toda vida pela escritora brasileira para a sua poesia e que ela consegue vislumbrar na obra de sua contemporânea.

\section{Considerações finais}

$\mathrm{O}$ interesse de Henriqueta pelas escritoras latino-americanas demonstra a necessidade de rever discursos críticos sobre a poetisa brasileira que ainda insistem em apontá-la como a "dama da literatura", a "poetisa da morte", atrelando-a ao campo do etéreo, do efêmero sem dar a devida atenção aos outros lugares transitados por Henriqueta como o da crítica literária, por exemplo, que merece estudos mais aprofundados. Os ensaios de Henriqueta mostram que já nas primeiras décadas do século XX ela se manifestou sobre desafios enfrentados pela mulher escritora e sobre as particularidades da poesia produzida pelas contemporâneas.

\section{Resumen}

En este trabajo nos proponemos analizar ensayos de Henriqueta Lisboa sobre escritoras latinoamericanas con el objetivo de reflexionar sobre la postura de la ensayista como crítica de obras de otras poetisas. Para la fundamentación de las reflexiones buscamos fundamento teórico en Michelle Perrot, Norma Telles, Nildiceia Rocha, Del Priore, entre otros, sobre el género y la poesía de autoría femenina. Observamos el pionerismo de Henriqueta cuando considera en sus ensayos, sin perder de vista las condiciones y imposiciones sociales, los esfuerzos de las escritoras para hacer de sus escrituras un medio para conseguir vez y voz. También destacamos el respeto y la admiración de la ensayista por la poesía de sus contemporáneas. En ningún momento, la ensayista se coloca de modo a estigmatizar a la producción literaria de las poetisas, algunas con estilo 
muy diferente del adoptado por la poetisa mineira, por el contrario, vemos el énfasis en los aspectos expresivos que marcan la singularidad de cada poetisa. Muchos de estos aspectos serían reafirmados por otros críticos en estudios posteriores.

Palabras clave: Henriqueta Lisboa. Ensayo. Poesía. Poetisas latinoamericanas. Género.

\section{Referências}

BOSI, Alfredo. História concisa da literatura brasileira. São Paulo: Cultrix, 1994.

BOSI, Alfredo. Em torno da poesia de Cecília Meireles. In: GOUVÊA, Leila V. B. (Org.) Ensaios sobre Cecília Meireles. São Paulo: Humanitas; FAPESP, 2007.

DAMASCENO, Darcy. Poesia do sensível e do imaginário. In: MEIRELES, Cecília. Obra poética. Rio de Janeiro: Nova Aguilar, 1993.

DEL PRIORE, Mary. História das Mulheres: as vozes do silêncio. In: FREITAS, M. C. (Org). Historiografia brasileira em perspectiva. 4 ed. São Paulo: Contexto, 2001.

DUARTE, Constância Lima. Os anos de 1930 e a literatura de autoria feminina. In: WERKEMA, Andréa Sirihal et al (Org.). Literatura Brasileira: 1930. Belo Horizonte: UFMG, 2012.

EDWARDS, Jorge. Vida e Obra de Gabriela Mistral. In: MISTRAL, Gabriela. Poesias escolhidas. Tradução de Henriqueta Lisboa. Rio de janeiro: Delta, 1969. GALEANO, Eduardo. Mujeres. Madri: Alianza Cien, 1995.

GULLBERG, Hjalmar. Discurso de recepção por ocasião da entrega do Prêmio Nobel de Literatura a Gabriela Mistral. In: MISTRAL, Gabriela. Poesias escolhidas. Tradução de Henriqueta Lisboa. Rio de Janeiro: Delta, 1969.

LISBOA, Henriqueta. Musa hispano-americana. Revista da Semana, Rio de janeiro, 20 out. 1934.

LISBOA, Henriqueta.Convívio poético. Belo horizonte: Imprensa Oficial, 1955.

LISBOA, Henriqueta .(Trad.) In: MISTRAL, Gabriela. Poesias escolhidas. Tradução de Henriqueta Lisboa. Rio de janeiro: Delta, 1969. 
LISBOA, Henriqueta. Vivência poética: Belo Horizonte: São Vicente, 1979.

LISBOA, Henriqueta. Obras completas (Poesia geral 1929-1983, v.I). São Paulo: Duas Cidades, 1985.

LUCAS, Fábio. A poética de Henriqueta Lisboa. In: LISBOA, Henriqueta. Casa de Pedra: poemas escolhidos. São Paulo: Ática, 1980.

MARQUES, Reinaldo. Henriqueta Lisboa: tradução e mediação cultural. In: Scripta - Revista do Programa de Pós-Graduação em Letras e do Centro de Estudos Luso-afro-brasileiros da PUC-Minas, v. 8, n. 15, p.205-212, 2004.

MEIRELES, Cecília. Expressão feminina da poesia na América. Três conferências sobre cultura hispano-americana. Ed. Departamento de Imprensa Nacional - MEC. Rio de Janeiro: Ministério de Educação e Cultura, 1959.

MISTRAL, Gabriela. Poesias escolhidas. Tradução de Henriqueta Lisboa. Rio de Janeiro: Delta, 1969.

NEVES, Ana Lúcia M. de Souza. Um atalho, uma clareira, coisa assim, no caminho: reflexões sobre os lugares de Henriqueta Lisboa no contexto da literatura brasileira. (Tese de Doutorado). Defendida em 2014 na UFPB/João Pessoa.

PERROT, Michelle. Minha história das mulheres. Tradução de Ângela M. S. Côrrea. São Paulo: Contexto, 2013.

QUEIROZ, Maria José de. A poesia de Juana de Ibarbourou. Belo Horizonte: Imprensa da Universidade de Minas Gerais, 1961.

ROCHA, Nildicéia Aparecida. A constituição da subjetividade feminina em Alfonsina Storni: uma voz gritante na América. São Paulo: UNESP, 2013.

SANTOS, Oswald de Araújo. Entrevista, 1968. Disponível em < WWW.letras. ufmg.br/henriquetalisboa/midia/entrevista02.htm> acesso em 20 agost. 2012.

SOUZA, Eneida Maria de (Org.). Correspondência Mário de Andrade \& Henriqueta Lisboa. São Paulo: Peirópolis/EDUSP, 2010.

STORNI, Alejandro Alfonso. Alfonsina Storni: entre dos primaveras. (Prefácio). In: Alfonsina Storni: Poesias - 50 Aniversário. Buenos Aires: SELA, 1990.

TELLES, Norma. Escritoras, escritas, escrituras. In: DEL PRIORE, Mary (org.) História das mulheres no Brasil. 9 ed. São Paulo: Contexto, 2010. 